\title{
Clean commercial transportation: medium and heavy duty fuel cell electric trucks
}

\author{
James Kast ${ }^{1 *}$, Ram Vijayagopal ${ }^{2}$, John J. Gangloff Jr. ${ }^{1}$, Jason Marcinkoski ${ }^{3}$ \\ ${ }^{1}$ Oak Ridge Institute for Science and Education \\ U.S. Department of Energy - Fuel Cell Technologies Office \\ 1000 Independence Avenue SW, Wasbington, DC 20585 USA \\ ${ }_{2}^{2}$ Argonne National Laboratory \\ 9700 South Cass Avenue B109, Lemont, IL 60439 \\ ${ }^{3}$ U.S. Department of Energy - Fuel Cell Technologies Office \\ 1000 Independence Avenue SW, Washington, DC 20585 USA \\ (*) Email: james.kast@ee.doe.gov Phone: 1 (202) 586-8477
}

\begin{abstract}
Recent advancements in sustainable transportation have led to the release of commercially available fuel cell electric vehicles (FCEVs). Examples such as the Toyota Mirai and the Hyundai Tucson are the culmination of many years of research and development. FCEVs provide a scalable pathway for clean hydrogen fuel to be used for transportation power generation. The following work presents modeling and analysis on the topic of commercial medium and heavy duty (MD and HD) vehicles that are operated using hydrogen fuel cells. This work studies how hydrogen fuel could be stored onboard MD/HD vehicles, and how these vehicles perform under various drive cycles that simulate real driving conditions for various vehicle classes and occupations. The aim is to provide an analysis framework to build increased understanding for which $\mathrm{MD} / \mathrm{HD}$ vehicle weight classes and vocations could provide economic and environmental benefits when utilizing hydrogen fuel cell technologies.
\end{abstract}

\section{Keywords}

Hydrogen fuel cells, medium and heavy duty trucks, fuel cell applications, bydrogen storage, drive cycle analysis

\section{Introduction}

Medium and heavy duty vehicles are responsible for 28 percent of petroleum consumption and nearly 26 percent of carbon dioxide emissions in the U.S. transportation sector [1]. Heavy duty vehicles also contribute about $36 \%$ of nitrogen oxides emissions nationally [2]. Increasing energy efficiency will be important to address carbon dioxide emissions, but transitioning a significant percentage of the sector to zero emission vehicles (ZEVs) will be necessary to meet climate change goals by the end of the century [3]. This is especially important considering that the U.S. Energy Information Administration projects an 80\% increase in truck miles between 2010 and 2050 [1]. Although hydrogen fuel cells have been suggested as an important strategy for reducing petroleum use and emissions from MD/HD vehicles [4], their performance and feasibility remain relatively unclear compared to other powertrains. However, hydrogen fuel cell technologies are promising, because they provide the ability to scale up power delivery for minimized increased weight, when compared to battery electric vehicles. The large number of truck body types, weight classes, and vocational uses results in a large potential design space.

The size and impact of the MD/HD sector creates the desire for improved fuel economy and reduced emissions. A few examples in the literature have focused on vehicle hybridization to achieve this goal [5] [6]. A recent study focused more on battery electric trucks in terms of life cycle implications [7]. Fuel cell technology along with other alternative and conventional powertrains have been compared in terms of market penetration, economics, and environmental factors, to further assess the future outlook and potential impacts of the different technologies [8] [9] [10].

Abbreviations

COPV: Composite Overwrapped Pressure Vessel

FCET: Fuel Cell Electric Truck

L/D: Length to Diameter Ratio

MD/HD: Medium and Heavy Duty

NREL: National Renewable Energy Laboratory

VIUS: Vehicle Inventory and Use Survey 
Utilizing a fuel cell onboard heavy duty trucks as an auxiliary power unit (APU) is one potential application of the technology. The purpose of the APU is to reduce or eliminate engine idling by generating the necessary power with a zero emissions technology such as a hydrogen fuel cell. Since long haul trucks and other MD/HD vehicle vocational uses require long periods of engine idling, the fuel consumption and greenhouse gas emissions (GHG) are a concern. The market feasibility and techno-economic aspects of fuel cell APUs have been studied in the literature [11] [12] [13] [14] [15] [16] [17]. Overall, fuel cell APUs are a feasible technology that could provide emissions and cost benefits. The topic of fuel cell electric buses (FCEBs) has also been studied in the literature [18] [19] [20] [21] [22] [23]. These studies investigated the feasibility of converting a bus fleet to FCEBs, along with lessons learned from real FCEB fleet operations. The bus market is targeted because of central refueling at a home base facility, and predictable daily routes. These factors are important in the early market for hydrogen because of the limited refueling infrastructure and the desire to collect consistent operational data. Other truck markets that operate in a similar fleet method with a central hub (e.g. delivery trucks and refuse trucks) could also be leveraged in the early markets. A number of detailed studies have focused on fuel cell range extender applications to improve the usability of pure electric drivetrains [24] [25] [26] [27]. These works considered hybrid system component design, vehicle optimization, and economic value.

Although fuel cell technology has been consider for some applications in the MD/HD sector, a market wide study of fuel cell dominant powertrains would provide an insightful design space to inform future research and relevant stakeholders. Outputs of this analysis include fuel cell system sizing, complete vehicle performance metrics, fuel economy, and vehicle range of the representative vehicles. Results of this analysis demonstrate the technical feasibility of fuel cell electric trucks (FCETs) across a wide range of the MD/HD vehicle market, and will help set realistic technical and design targets to drive the industry. The overarching goal of the project is to demonstrate the technical feasibility of FCETs by comparing performance to conventional diesel trucks, and to identify technical and economic targets that allow for commercialization in the future.

\section{Methodology}

The analysis is divided into four parts to capture the important concepts related to FCETs. This chronological organization, as shown in Figure 1, displays the relationship between each analysis topic. Each major task will be explained in greater detail in the next sections.

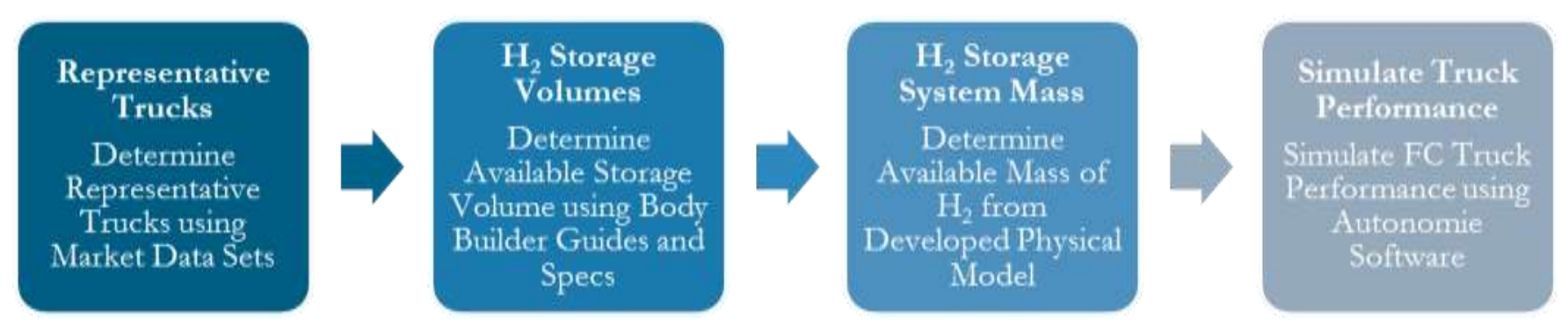

Figure 1: Flowchart of FCET modeling framework.

This paper assesses the suitability of converting a representative sample of MD/HD diesel trucks into FCETs, while considering truck dimensions and clearances, hydrogen storage tank design, drive cycles and necessary range, average payload, and other guiding metrics. The analysis has four parts. First, candidate truck vehicle types for conversion to fuel cell electric powertrains are identified by their current market size using the Vehicle Inventory and Use Survey (VIUS) [28]. Actual representative vehicles are chosen for each candidate vehicle. Second, for each candidate truck type, the available packaging volume for onboard storage is assessed and a variety of potential gaseous storage tank configurations and sizes are examined. This analysis demonstrates the customizability of trucks, which allows for optimal hydrogen storage design based on vehicle size and vocation. Third, the potential tank sizes are used to estimate the weight and capacity of gaseous storage at 350 and 700 bar pressures. These mass estimations provide the basis for vehicle range calculations, which is an important metric in determining the feasibility of each FCET. Lastly, the Autonomie vehicle model from Argonne National Laboratory is used to construct computer simulations of each vehicle type across a number of standard drive cycles while maintaining vehicle performance [29]. The results of this simulation work will be the focus of this paper.

\subsection{Representative Trucks}

The MD/HD truck market spans a wide range of vehicle weight classes and vocational uses. This wide diversity in vehicle weight class and vocation makes it difficult to consolidate the range of performance needs. Examples are shown 
in Figure 2. In order to conduct analysis, a sample set of 12 representative trucks was chosen to capture the major market segments within the MD/HD space. The selection of these 12 trucks is based on market information obtained from the VIUS data, which breaks down the MD/HD truck market by common vocational uses for each vehicle weight class. The survey reached out to truck and fleet operators to obtain insight about truck use throughout the U.S. The daily trip range specified by survey responders helped guide onboard hydrogen storage needs, which are described in later sections. By identifying major market segments, such as a Class 4 delivery van, actual representative truck models were chosen to conduct analysis and feasibility studies for FCETs. Aggregating the results from the 12 representative trucks provides broader insight to the benefits, challenges, and overall feasibility of FCETs in today's $\mathrm{MD} / \mathrm{HD}$ market.

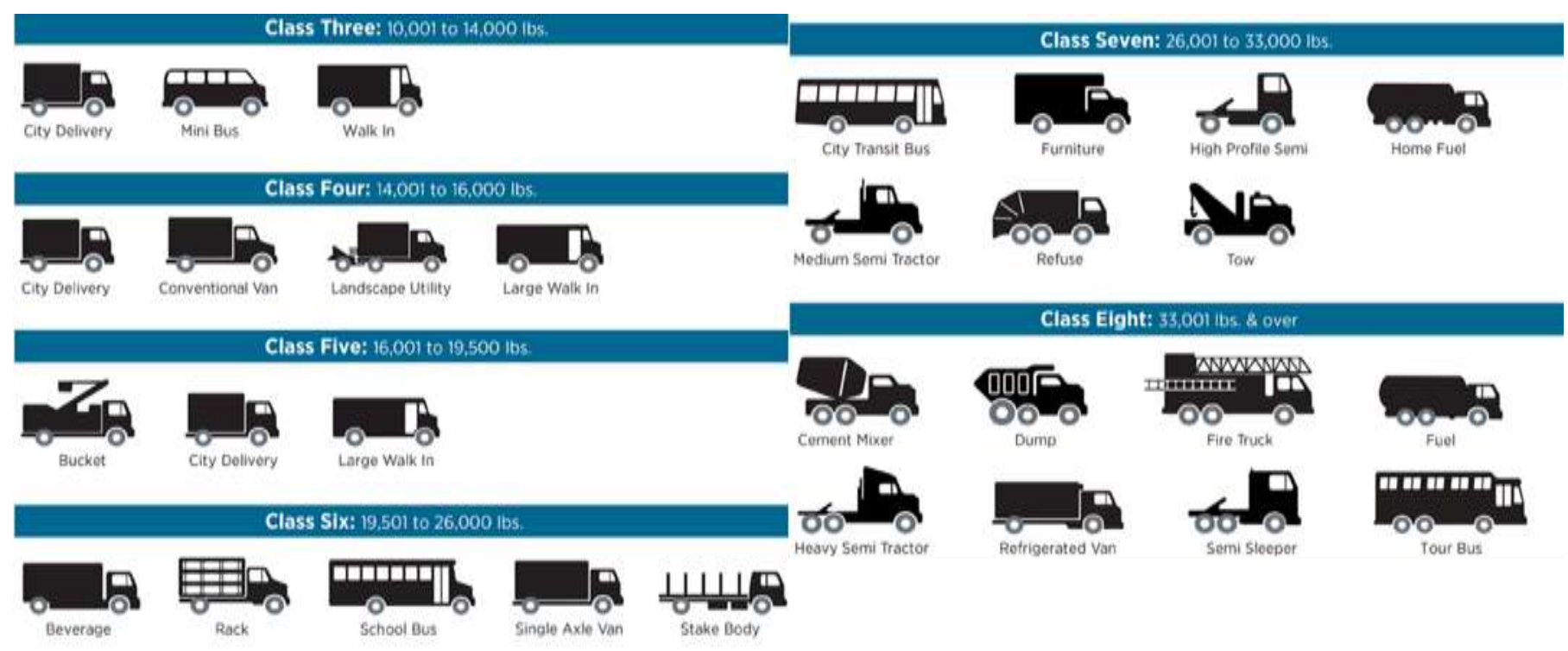

Figure 2: MD/HD example classes and vocational uses (Credit: Alternative fuels data center, Department of Energy Office of Energy Efficiency and Renewable Energy).

\subsection{Packaging Hydrogen Onboard}

With the representative trucks identified, the next major step is to investigate how to package fuel cell system components onboard the vehicles. The hydrogen storage will be a major factor for packaging considerations, since the trucks are designed as fuel cell dominant powertrains that rely on the energy stored as hydrogen fuel. A small battery is present in the system to provide hybrid and regenerative braking capabilities, but it provides very little usable energy for vehicle range considerations. After brief analysis, it is assumed that there can be sufficient space between the frame rails and in the frontal area to house the motor, fuel cell stack, high voltage battery, and major balance of plant components. Further analysis is needed to quantify the available volume for packaging hydrogen storage tanks onboard.

A number of tank locations and configurations were considered to investigate the potential packaging volume for hydrogen storage. This included tanks located on the side rails, between the frame rails, behind the cab, and on top of the cab. Some locations are ideal for certain vehicles, for example: on top of a bus similar to current compressed natural gas $(\mathrm{CNG})$ buses, and behind the cab of large tractor trailers. However, each truck chassis can be used for many applications and only one tank location along the side rails remains available across most of the MD/HD market. The back of cab configuration is common for CNG heavy duty vehicles; however, this configuration is not applicable for many medium duty vehicles unlike the side rail configuration. The maximum volume available on the side rails is determined for each truck based on dimensional constraints of the chassis. Available wheelbase, minimum ground clearance, and the width of two tires provide general guidelines for volume constraints. Potential tank dimensions are determined from these metrics which were obtained from OEM body builder guides containing dimensional information. Ample buffer distances around the tank are added before finalizing potential tank dimensions. The total available storage volume can be estimated assuming a dual tank configuration with one tank along each side rail of the truck. Figure 3 shows examples of side rail and back of cab hydrogen storage locations schematically. Considerably more hydrogen could be stored onboard the vehicle if multiple tank locations were utilized, but this is not considered within the analysis for the initial modeling effort. The design implications of FCETs in a highly variable and customizable $\mathrm{MD} / \mathrm{HD}$ market will be discussed in greater detail in future related work. 


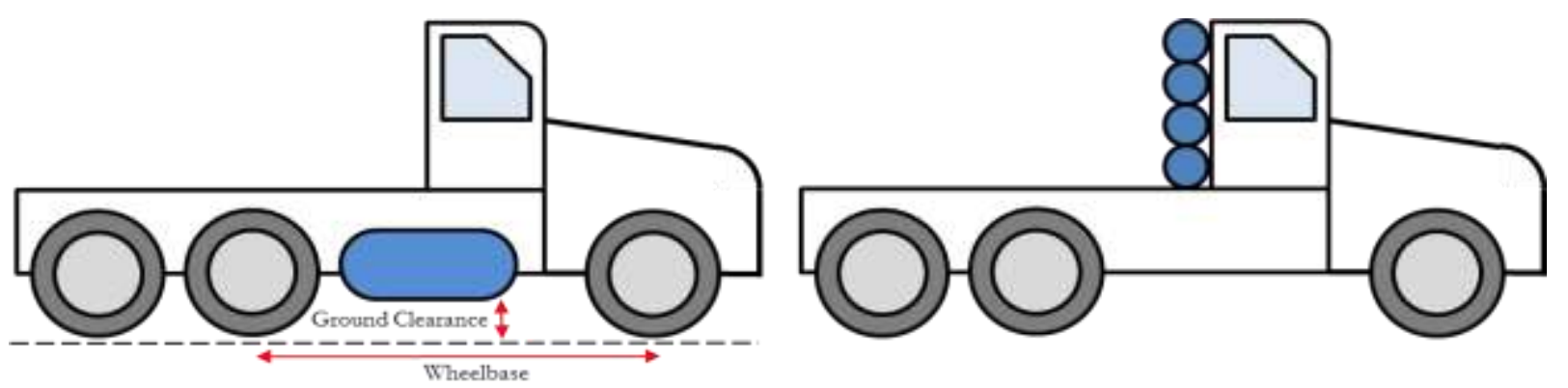

Figure 3: A schematic showing a potential site for compressed hydrogen storage on-board a FCET at the side rail (left) and back of $\mathrm{cab}$ (right) in dark blue color. FCET ground clearance and wheelbase are key parameters for sizing available compressed hydrogen storage packaging volume.

\subsection{Storage Tank Mass Calculations}

With sample maximum tank dimensions determined for each truck, the next step is to calculate the mass of the storage tanks and the amount of stored hydrogen onboard. The amount of stored hydrogen is used to estimate the overall vehicle driving range. A model was developed to estimate these values for Type IV Composite Overwrapped Pressure Vessels (COPV). These kind of Type IV compressed hydrogen storage tanks consist of a polymeric liner overwrapped with carbon fiber reinforced polymer composite material. This type of tank technology allows for high pressure storage up to $700 \mathrm{bar}$, while weighing less compared to traditional metallic storage materials. Figure 4 shows the manufacturing process known as filament winding being performed to manufacture a COPV for on-board light duty vehicle hydrogen storage. A carbon fiber filament is wetted with polymer resin (i.e. epoxy) and is wound around the interior polymer liner that formed the pressure vessel tank shape. The resin hardens after the vessel is completely wound, forming the COPV structure.

The high strength and low weight carbon fiber composite provides the mechanical support needed to handle the standard 700 bar compressed hydrogen storage. The carbon fiber composite material could be prohibitively expensive for the MD/HD market. A goal of this work is to establish a modeling framework to determine how much hydrogen can be stored for a given $\mathrm{MD} / \mathrm{HD}$ packaging volume. If lower pressures can be used to provide enough hydrogen fuel (i.e. 350 bar), then the amount of needed carbon fiber composite can be reduced. This would greatly reduce the cost of the on-board tanks and reduce the overall cost barrier for using hydrogen fuel cell technologies on-board MD/HD vehicles.

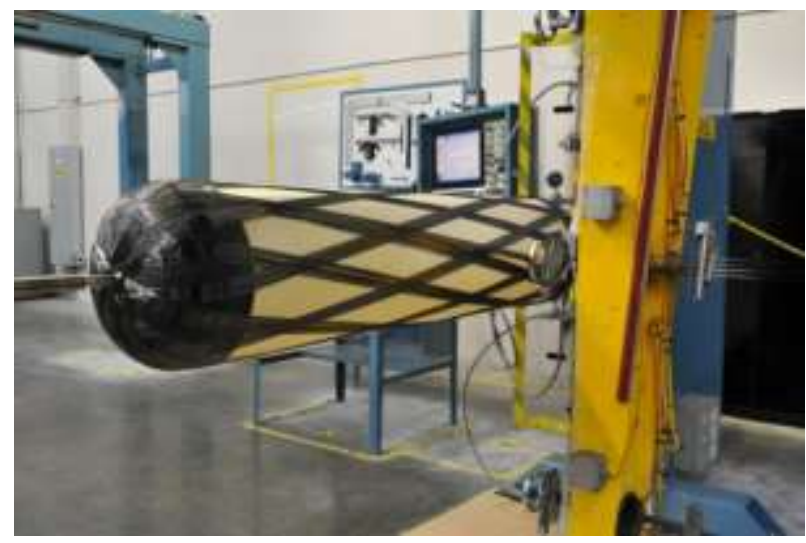

Figure 4: Picture of a Composite Overwrapped Pressure Vessel (COPV) manufacturing process via filament winding. (Credit: Quantum Technologies, 2012)

Calculating the mass of stored hydrogen requires the density of hydrogen at high pressures (i.e. 350 and 700 bar). Data collected from NIST provides an accurate real gas value for the density of hydrogen at these high pressures [30]. A summary of real gas measurements versus ideal gas calculations can be seen in Figure 5. Mass estimates can be made for 350 and 700 bar storage, which follows current hydrogen refueling infrastructure protocol for both light duty and MD/HD vehicles (SAE J2601) [31] [32]. The current hydrogen station delivery pressure standard for light duty vehicles is 700 bar. The goal for MD/HD vehicles to use 350 bar storage if enough hydrogen fuel is stored for the occupation duty cycle. This storage pressure reduction would reduce material cost, fuel cost, and provide a conservative first estimation for the amount of hydrogen that can be stored onboard each truck. Due to volumetric constraints, 700 bar is usually necessary for vehicles smaller than Class 4. Because of tight packaging in vehicles Class 3 and below, tank design 
in this work considers 700 bar storage for all vehicles that are Class 3 and below, and 350 bar storage for vehicles Class 4 and above.

The mass of the storage tanks themselves is calculated using a material stress calculation that determines the necessary wall thickness of the tank. The total mass of the tank is calculated using the wall thickness, tank dimensions, and density of the materials. A key assumption is that the tank walls are considered thin. This is valid if the tank length to diameter ratio, $\mathrm{L} / \mathrm{D}<10$. If the tank length to diameter ratio is $>10$, the tank can be considered thick walled and have a non-uniform mechanical strain through the thickness - thus requiring more robust stress analysis to determine the necessary wall thickness (i.e. Finite Element Analysis). Storage mass calculations are described in greater detail in related work [33]. Tank mass information will be utilized during vehicle simulations to more accurately capture the performance of the vehicle. Mass approximations will be made for other powertrain components, which is briefly described in the next section.

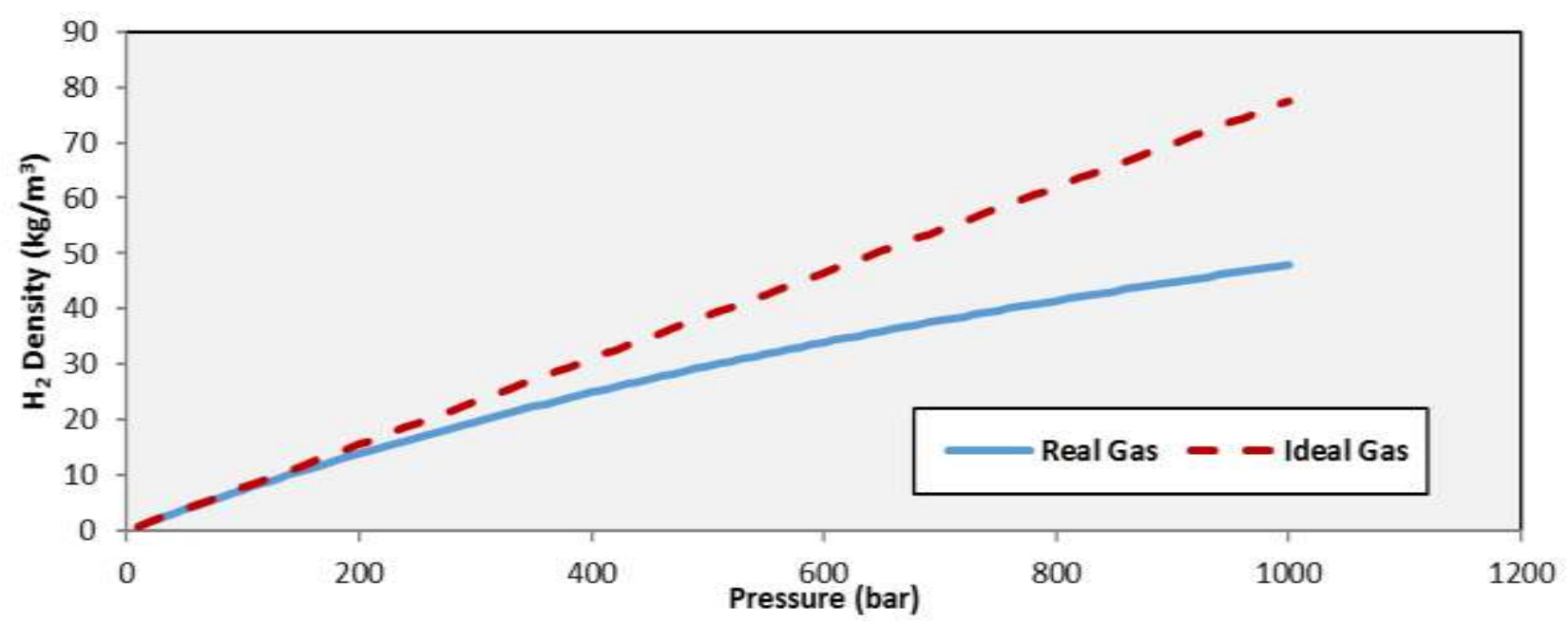

Figure 5: A comparison of ideal gas and real gas assumptions. For the standard hydrogen delivery storage pressures of 350 bar and 700 bar, ideal gas law assumptions are too inconsistent with real gas measurements. Densities are calculated at $288 \mathrm{~K}$ using the NIST Chemistry WebBook.

\subsection{Vebicle Simulation and Design}

The final design step is to size appropriate powertrain components and simulate vehicle performance using Autonomie software [29]. With the hydrogen storage tanks determined, the major powertrain components remaining include the fuel cell stack, motor, and high voltage battery. These components replace the engine, fuel tank, and transmission of a traditional diesel vehicle.

Powertrain component sizing requirement is to meet or exceed baseline vehicle performance metrics. This is assumed to be a good substitute for verifying all potential use cases for different classes and vocations. Baseline vehicles are simulated to determine their performance over three major metrics including acceleration, cruising speed, and grade speed. The acceleration time is determined for $0-30 \mathrm{mph}$ and $0-60 \mathrm{mph}$ performance, cruising speed at typical highway operation, and grade speed is the maximum sustainable speed over an 11 mile drive cycle at $6 \%$ grade [34]. These baseline vehicle performance metrics provide the criteria for sizing a fuel cell dominant powertrain. The sizing process [35], assumes a fuel cell dominant vehicle design, where fuel cell is the primary source for electric power in the vehicle, with battery being used to meet any transient peak demands. Battery is also used for regenerative braking. This battery operation is similar to current hybrid electric vehicles on the market. Mass estimations are made for each of the new powertrain components by using power density values for each component [36] [37] [38]. Direct mass comparisons of the designed FCET to the conventional truck shows that the overall mass remains similar without sacrificing any cargo weight.

An example of a motor sizing plot is shown in Figure 6. It shows that the continuous operating region of the motor is capable of meeting the continuous operating loads (cruise and grade speed), and transient operating region is used for the peak demands such as acceleration performance. The overall speed reduction ratio and motor power is selected to ensure the motor rating is the minimum value needed to meet the performance.

The virtual vehicles with appropriately sized powertrain components are then simulated over real world drive cycle data obtained from the National Renewable Energy Laboratory (NREL) Fleet DNA database to observe the simulated real world performance of the trucks on representative drive cycles [39]. The data for each cycle includes real time 
information on vehicle speed (acceleration) and grade over full day operation. Simulations over drive cycles shows how well the FCET follows the speed trace and daily range. An example drive cycle is shown in Figure 7. Meeting the necessary range of actual truck routes is a major metric to determine the feasibility of FCETs. Detailed component sizing and simulation results are provided in the next sections.

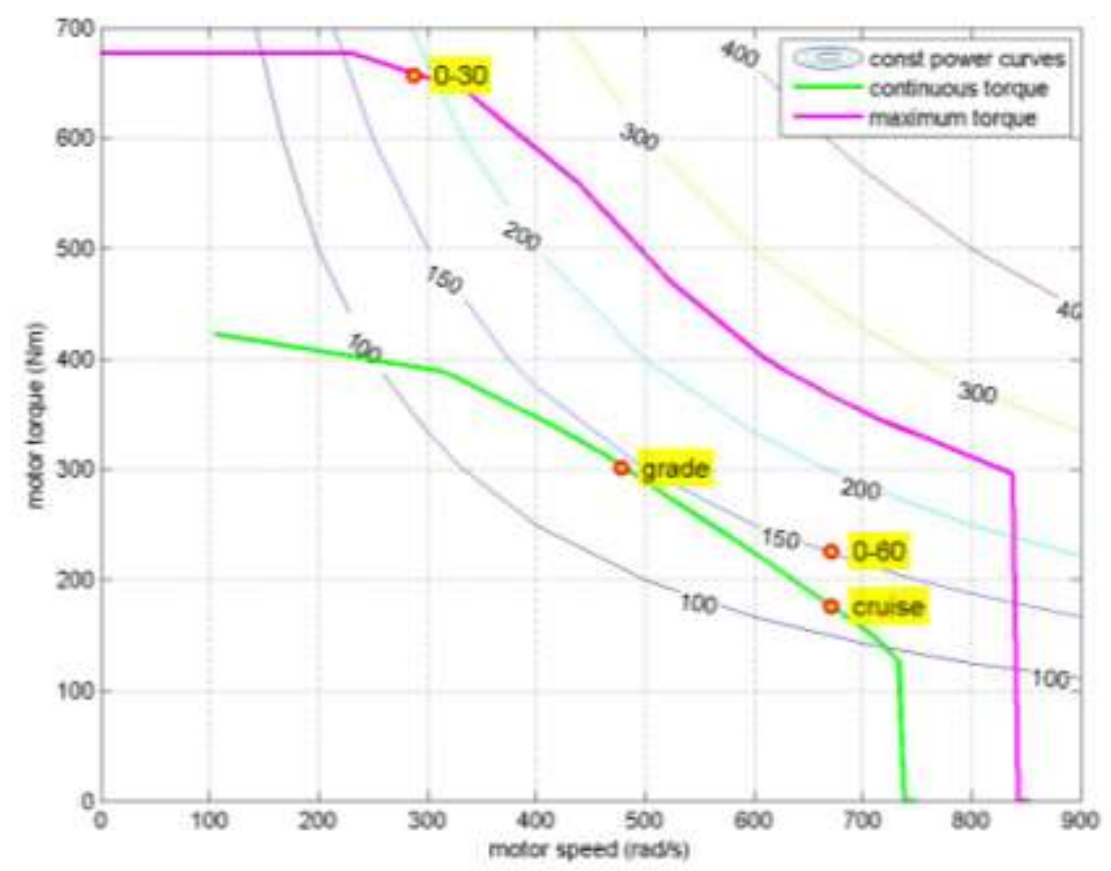

Figure 6. Electric motor is sized to satisfy four important performance criteria.

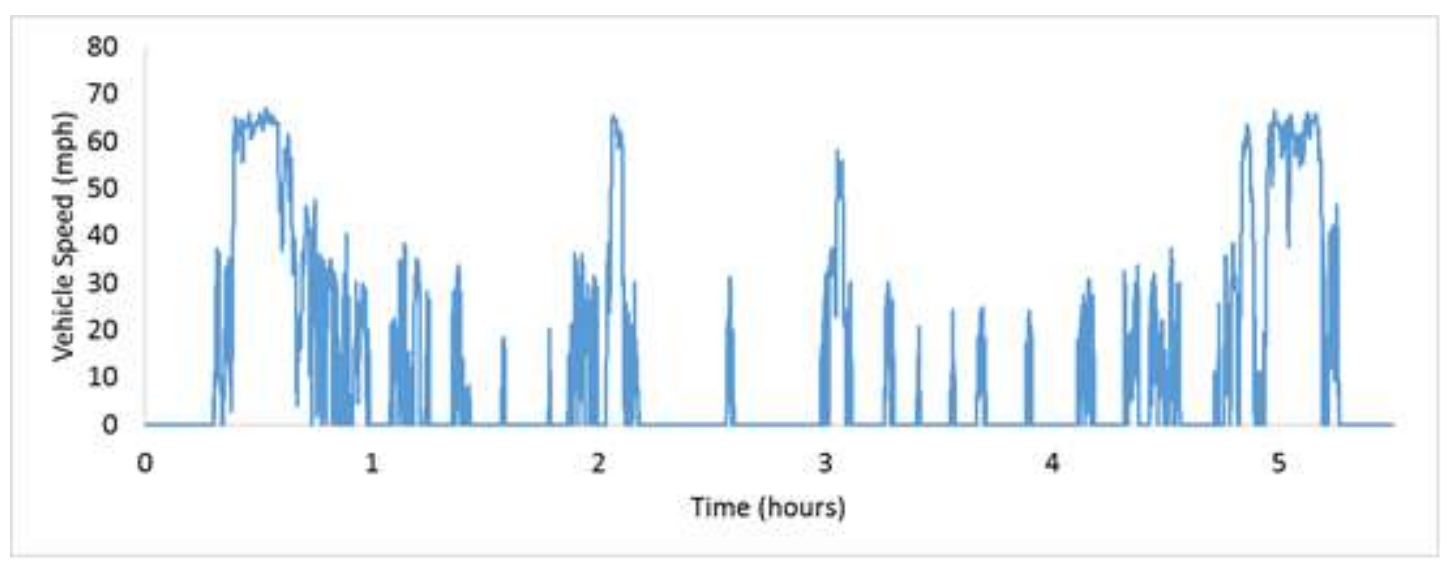

Figure 7. A sample drive cycle from the FleetDNA database for a delivery truck.

\section{Results and Discussion}

The results in this study offer a unique contribution to the existing literature by combining multiple levels of market research and vehicle analysis in order to demonstrate the feasibility of fuel cell dominant MD/HD vehicles. As discussed earlier in the paper, range extenders, APU's, and hybrid powertrains have been explored in the literature as potential applications for trucks. However, a detailed design process for fuel cell dominant trucks remains unexplored, and this work attempts to capture potential vehicle designs that can meet or exceed the needs of the MD/HD market. Once the list of representative trucks is determined to capture the major markets within the MD/HD sector, detailed analysis and design for each vehicle is done to locate and size the hydrogen storage onboard, size the fuel cell powertrain components, and simulate each virtual vehicle with real world drive cycle data. The broad design space created from this work allows researchers and industry to better understand the opportunity of fuel cell dominant powertrains for $\mathrm{MD} / \mathrm{HD}$ applications.

\subsection{Representative Truck Summary}

The summary information provided in Table 1 shows the final component sizes needed to meet or exceed the incumbent vehicle performance. Cruise speed and grade speed performance are matched based on continuous power 
ratings, and the electric powertrain results in increased acceleration performance in most cases. Since the vehicle components are sized to the meet or exceed the incumbent vehicle specifications, the designed FCETs will meet or exceed the performance of the baseline vehicle. The stored hydrogen requirement is based on meeting the VIUS daily range of each vehicle assuming highway operation fuel economy for conservative calculations. This fuel economy tends to be the worst case value due to poor aerodynamics and lack of regenerative braking opportunities. The summary plot in Figure 8 provides a visual representation of the stored hydrogen, fuel cell power, and motor power requirements, where the area of the bubbles display relative motor size. Note that many of the truck classes and vocations require 25 $\mathrm{kg}$ or less hydrogen storage to meet their daily range, and $180 \mathrm{~kW}$ or less fuel cell power to meet performance needs. The two long haul tractor trailers are the major exceptions that require significantly more hydrogen and fuel cell power to meet performance and daily range requirements with a single refueling event. Other vocational exceptions may also require greater fuel cell power to meet the needs of highly demanding applications.

Table 1: Summary representative vehicle specifications.

\begin{tabular}{|c|c|c|c|c|c|}
\hline Vehicle & $\begin{array}{l}\text { Continuous } \\
\text { Motor Power } \\
(\mathrm{kW})\end{array}$ & $\begin{array}{c}\text { Fuel Cell } \\
\text { Power } \\
(\mathrm{kW})\end{array}$ & $\begin{array}{c}\text { Battery } \\
\text { Power (kW) }\end{array}$ & $\begin{array}{c}0-30 \\
\text { Acceleration } \\
\text { Improvement } \\
(\%)\end{array}$ & $\begin{array}{c}\text { 0-60 } \\
\text { Acceleration } \\
\text { Improvement } \\
(\%)\end{array}$ \\
\hline Class 2 Van & 128 & 147 & 6 & 18 & 22 \\
\hline Class 3 Enclosed Van & 157 & 149 & 62 & 11 & 26 \\
\hline Class 3 School Bus & 175 & 180 & 76 & 10 & 16 \\
\hline Class 3 Service & 146 & 165 & 4 & 37 & 23 \\
\hline Class 4 Delivery Van & 151 & 166 & 59 & 4 & 27 \\
\hline Class 5 Utility & 210 & 253 & 8 & 134 & 17 \\
\hline Class 6 Construction & 151 & 170 & 30 & 23 & 21 \\
\hline Class 7 School Bus & 146 & 145 & 56 & 20 & 13 \\
\hline Class 8 Construction & 186 & 139 & 57 & 28 & 0 \\
\hline Class 8 Linehaul & 349 & 363 & 47 & 24 & 15 \\
\hline Class 8 Refuse & 256 & 273 & 94 & 16 & 27 \\
\hline Class 8 Tractor Trailer & 250 & 247 & 95 & 22 & 11 \\
\hline
\end{tabular}




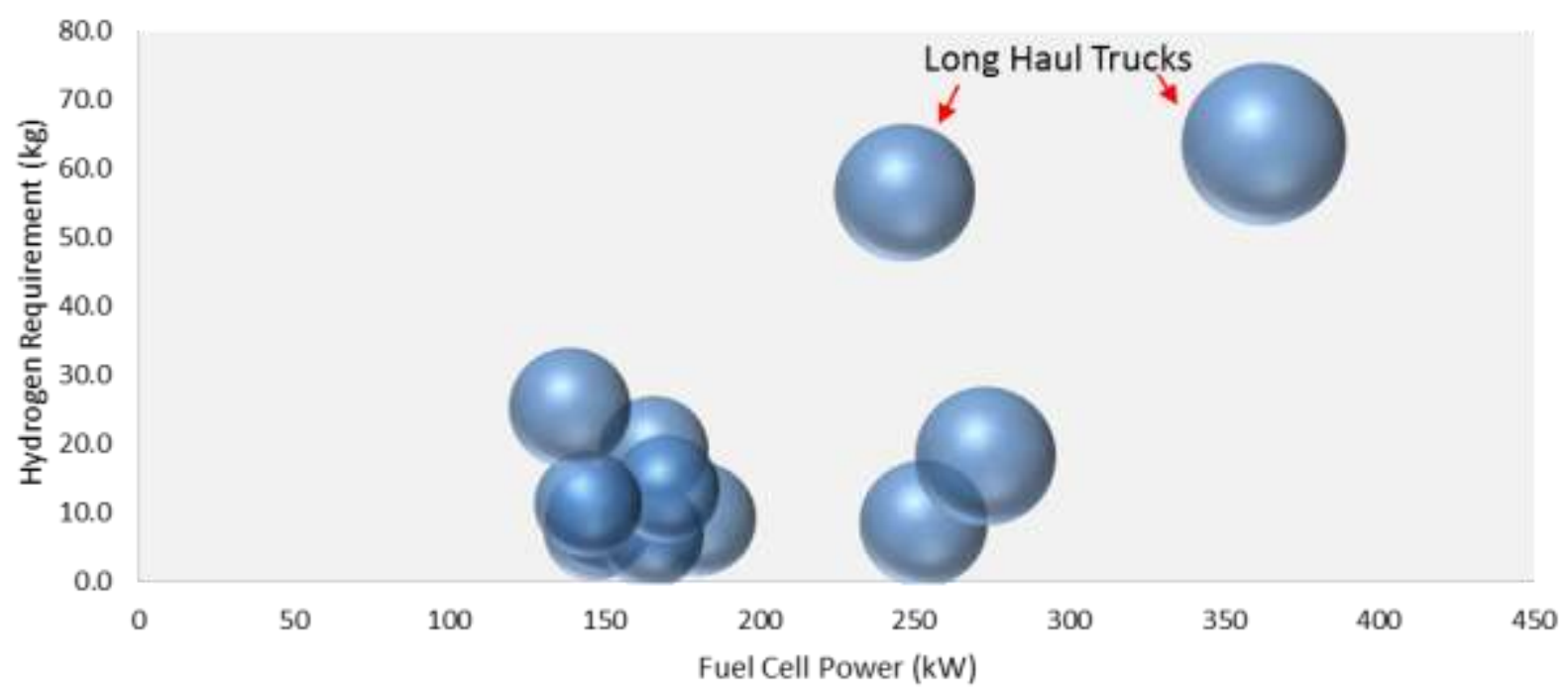

Figure 8: Powertrain component sizing. Area of the bubbles is proportional to motor size.

\subsection{Drive Cycle Analysis}

Designing FCETs that do not compromise performance compared to incumbent technology is vital to demonstrating feasibility for real world operation. Each of the designed representative FCETs is simulated over numerous drive cycle data, which is collected by NREL and added to the Fleet DNA database [39]. Each unique drive cycle represents a conventional truck operated for a regular daily purpose. Figure 9 shows the aggregated daily range of one truck category of interest. The redline represents the percentage of drive cycles that can be met based on the designed maximum range of the vehicle.

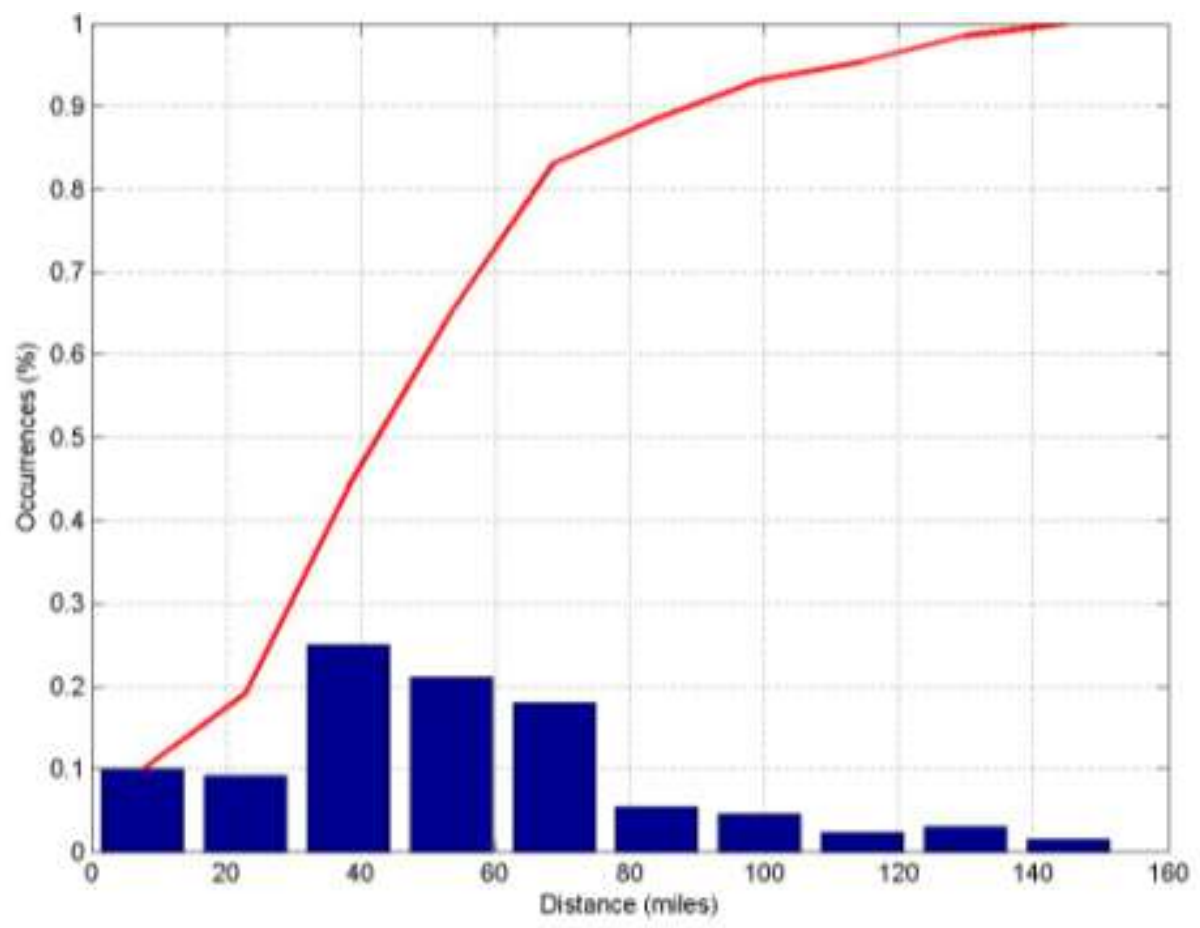

Figure 9: Aggregated daily range of class 4 delivery vans from the FLEET DNA database.

Figure 10 shows the variability of vehicle range needs within one truck category, where each bar in the plot represents one trucks daily drive cycle. The corresponding fuel economy and necessary stored hydrogen are also shown for each case. 

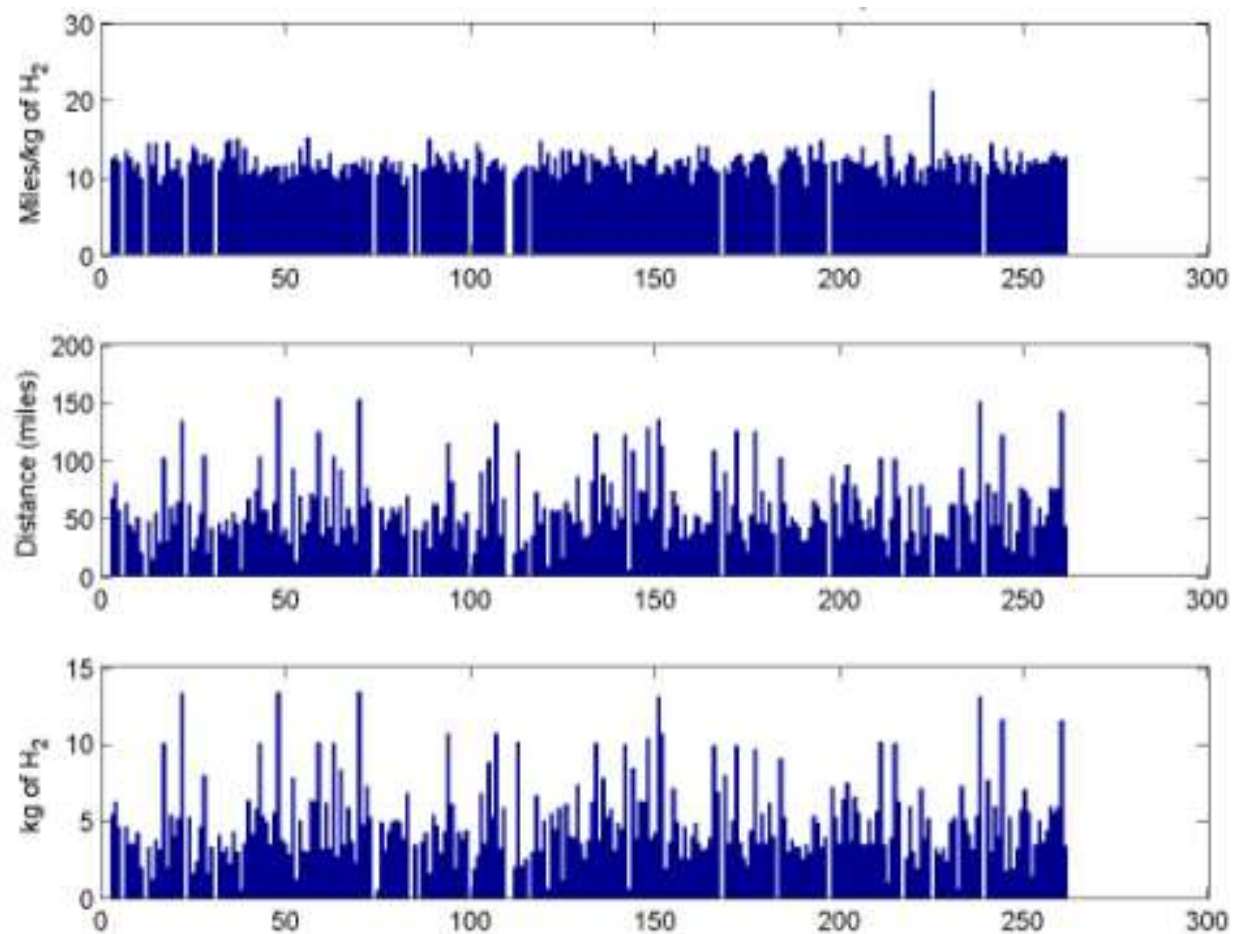

Figure 10: Summary of drive cycle characteristics for class 4 delivery vans.

Table 2: Representative vehicle range considerations from aggregated drive cycle data

Vehicle

Onboard Hydrogen

Storage (kg)

\section{Average Fuel \\ Economy \\ (miles/kg of H2)}

Average

Range

(miles)
$\%$ of cycles met by vehicle
Class 2 Van

Class 3 Enclosed Van

Class 3 School Bus

Class 3 Service

Class 4 Delivery Van

Class 5 Utility

Class 6 Construction

Class 7 School Bus

Class 8 Construction

Class 8 Linehaul

Class 8 Refuse

Class 8 Tractor Trailer
7.2

8.9

9.1

6.7

19.1

8.5

13.5

11.3

25.3

63.7

18.2

56.6
23.6

15.5

19.5

15.7

11.9

11.1

13.5

11.1

9.2

5.5

6.4

6.2
170

138

177

$100 \%$

105

$100 \%$

227

$100 \%$

94

$95 \%$

$96 \%$

$99 \%$

125

233

$100 \%$

350

$40 \%$

116

$95 \%$

351

$40 \%$ 
The aggregated summary information in Table 2 provides the average values across the 12 representative vehicles that contribute to daily range considerations. The onboard storage amount was determined based on range considerations from the VIUS database. The specified onboard storage amount will be able to meet at least $90 \%$ of the daily trips in each category from the survey based on the worst case fuel economy. The onboard storage amount shown in the table does not represent the maximum potential onboard hydrogen storage for each vehicle class. This will be described in more detail in the conclusion. The average range displays the capability of each vehicle based on the designed hydrogen storage, and simulated average fuel economy from all drive cycles in each truck category. The major output of the table is the percentage of real world trips that can be met by the FCET. Note that many simulated vehicles meet the vehicle range needs of at least $95 \%$ of the routes, and a number of vehicles are able to meet $100 \%$ of the routes. The Class 8 trucks that run longer distances cover only $40 \%$ of their daily drives based on the current estimate of hydrogen storage, but it is important to consider unknown parameters in the data. NREL Fleet DNA data shows that over half of Class 8 trucks drive over 400 miles a day, yet each stop is not documented in this data collection. This makes it difficult to estimate how much of each drive cycle occurs without refueling. The potential for overnight or multiple day operation could also have an impact. Although the standard fuel tanks in conventional Class 8 trucks provide a range of about 400 miles, it is possible to configure these trucks with large tanks that can achieve a range of 1000 miles [40].

Considerably more hydrogen could be packaged onboard many of the trucks by increasing tank size within the available storage volume, adding additional tanks in other feasible locations, and increasing storage pressure from 350 bar to 700 bar. Packaging volume considerations for hydrogen storage will be described in greater detail in future publications from related work.

\section{Conclusions}

The analysis has shown that FCETs are feasible for many truck classes and vocational uses without compromising any performance characteristics compared to conventional powertrain technologies. In fact, in many cases, vehicle performance is improved due to the operation of electric drivetrains. Onboard hydrogen storage is able to satisfy the vehicle range requirements for at least $90 \%$ of daily routes based on data collected from U.S. census survey results and real world drive cycle data collection. Hydrogen storage can also be significantly increased on many larger trucks by taking advantage of unused storage space behind the cab and under the chassis, and by increasing the storage pressure. These opportunities to further increase onboard storage allow FCETs to meet the vehicle range requirements of more demanding daily routes.

The overarching goal of the project is to demonstrate the technical feasibility of FCETs, and to identify technical and economic targets that allow for commercialization in the future. Setting targets that allow systems to be cost competitive with incumbent technology that can cover a majority of the MD/HD truck market is necessary. Future work on this project could entail techno-economic analysis to identify major cost barriers of the technology. Setting accurate technical and cost targets for the industry is a vital first step to enable market penetration of FCET's into the $\mathrm{MD} / \mathrm{HD}$ sector.

\section{Acknowledgments}

The authors acknowledge the Department of Energy (DOE) Office of the Secretary administered by the Oak Ridge Institute for Science and Education (ORISE) for the DOE. ORISE is managed by Oak Ridge Associated Universities (ORAU) under DOE contract number DE-AC05-06OR23100. Argonne, a U.S. Department of Energy Office of Science laboratory, is operated under Contract No. DE-AC02-06CH11357. The Department of Energy will provide public access to these results of federally sponsored research in accordance with the DOE Public Access Plan (http://www.energy.gov/downloads/doe-public-access-plan) All opinions expressed in this paper are the author's and do not necessarily reflect the policies and views of DOE, ORAU, or ORISE.

\section{References}

[1] Energy Information Administration, Annual Energy Outlook, 2015. http://www.eia.gov/forecasts/aeo/.

[2] EPA (2015), National Criteria Pollutant Inventory. Available online at: http://www3.epa.gov/ttnchie1/net/2011inventory.html.

[3] Yang, C., et al., Meeting an $80 \%$ reduction in greenhouse gas emissions from transportation by 2050: A case study in California. Transportation Research Part D: Transport and Environment, 2009, 14(3): p. 147-156.

[4] California Air Resources Board, Vision for Clean Air: A Framework for Air Quality and Climate Planning, Public Review Draft, 2012. http://www.arb.ca.gov/planning/vision/docs/vision_for_clean_air_public_review_draft.pdf. 
[5] Antti Lajunen, "Fuel economy analysis of conventional and hybrid heavy vehicle combinations over real-world operating routes," Transportation Research Part D: Transport and Environment, Volume 31, August 2014, Pages 70-84, ISSN 13619209, http://dx.doi.org/10.1016/j.trd.2014.05.023.

[6] Zhiming Gao, David E. Smith, C. Stuart Daw, K. Dean Edwards, Brian C. Kaul, Norberto Domingo, James E. Parks II, Perry T. Jones, "The evaluation of developing vehicle technologies on the fuel economy of long-haul trucks, Energy Conversion and Management," Volume 106, December 2015, Pages 766-781, ISSN 0196-8904, http://dx.doi.org/10.1016/j.enconman.2015.10.006.

[7] Burak Sen, Tolga Ercan, Omer Tatari, "Does a battery-electric truck make a difference? - Life cycle emissions, costs, and externality analysis of alternative fuel-powered Class 8 heavy-duty trucks in the United States," Journal of Cleaner Production, Volume 141, 10 January 2017, Pages 110-121, ISSN 0959-6526, http://dx.doi.org/10.1016/i.jclepro.2016.09.046. (http://www.sciencedirect.com/science/article/pii/S0959652616313877)

[8] Kamila Romejko, Masaru Nakano, "Portfolio analysis of alternative fuel vehicles considering technological advancement, energy security and policy," Journal of Cleaner Production, Volume 142, Part 1, 20 January 2017, Pages 39-49, ISSN 09596526, http://dx.doi.org/10.1016/j.jclepro.2016.09.029.

[9] Markus F. Felgenhauer, Matthew A. Pellow, Sally M. Benson, Thomas Hamacher, "Economic and Environmental Prospects of Battery and Fuel Cell Vehicles for the Energy Transition in German Communities," Energy Procedia, Volume 99, November 2016, Pages 380-391, ISSN 1876-6102, http://dx.doi.org/10.1016/j.egypro.2016.10.128.

[10] Long Zhang, Jing Yu, Jingzheng Ren, Linmao Ma, Weishi Zhang, Hanwei Liang, "How can fuel cell vehicles bring a bright future for this dragon? Answer by multi-criteria decision making analysis," International Journal of Hydrogen Energy, Volume 41, Issue 39, 19 October 2016, Pages 17183-17192, ISSN 0360-3199, http://dx.doi.org/10.1016/j.ijhydene.2016.08.044.

[11] Brodrick, Christie-Joy, et al., "Evaluation of fuel cell auxiliary power units for heavy-duty diesel trucks," Transportation Research Part D: Transport and Environment, Volume 7, Issue 4, Pages 303-315. June 2002.

[12] Contestabile, Marcello, "Analysis of the market for diesel PEM fuel cell auxiliary power units onboard long-haul trucks and of its implications for the large-scale adoption of PEM FCs," Energy Policy, Volume 38, Issue 10, Pages 5320-5334, October 2010.

[13] Rahman, S.M., et al., "Impact of idling on fuel consumption and exhaust emissions and available idle-reduction technologies for diesel vehicles-A review," Energy Conversion and Management, Volume 74, Pages 171-182, October 2013.

[14] Brodrick, Christie-Joy, et al., "Potential Benefits of Utilizing Fuel Cell Auxiliary Power Units in Lieu of Heavy-Duty Truck Engine Idling," University of California Davis, Institute of Transportation Studies, January 2001.

[15] Lutsey, N, et al., "Markets for Fuel-Cell Auxiliary Power Units in Vehicles: Preliminary Assessment," Transportation Research Record: Journal of the Transportation Research Board, Volume 1842, 2003.

[16] Jain, S., et al., "Techno-economic analysis of fuel cell auxiliary power units as alternative to idling," Journal of Power Sources, Volume 160, Issue 1, Pages 474-484, September 2006.

[17] Agnolucci, Paolo, "Prospects of fuel cell auxiliary power units in the civil markets," International Journal of Hydrogen Energy, Volume 32, Issue 17, Pages 4306-4318, December 2007.

[18] Langford, B.; Cherry, C., "Transitioning a bus transit fleet to hydrogen fuel: A case study of Knoxville Area Transit," International Journal of Hydrogen Energy, Volume 37, Issue 3, Pages 2635-2643, February 2016.

[19] Folkesson, et al., "Real life testing of a Hybrid PEM Fuel Cell Bus," Journal of Power Sources, Volume 118, Issues 1-2, Pages 349-357, May 2003.

[20] Hu, et al., "Optimal Dimensioning and Power Management of a Fuel Cell/Battery Hybrid Bus via Convex Programming," IEEE Transactions on Mechatronics, Volume 20, Issue 1, Pages 457-468, July 2014.

[21] Fleck, W. (2016) Transportation/Propulsion/Demonstration/Buses: The Design of the Fuel Cell Powertrain for Urban Transportation Applications (Daimler), in Hydrogen Science and Engineering : Materials, Processes, Systems and Technology (eds Prof. Dr. D. Stolten and Dr. B. Emonts), Wiley-VCH Verlag GmbH \& Co. KGaA, Weinheim, Germany. doi: 10.1002/9783527674268.ch41.

[22] Sharaf, O.; Orhan, M., "An overview of fuel cell technology: Fundamentals and applications," Renewable and Sustainable Energy Reviews, Volume 32, Pages 810-853, April 2014.

[23] Bubna, P., et al., "Analysis, operation and maintenance of a fuel cell/battery series-hybrid bus for urban transit applications," Journal of Power Sources, Volume 195, Issue 12, Pages 3939-3949, June 2010.

[24] Diego Feroldi, Mauro Carignano, "Sizing for fuel cell/supercapacitor hybrid vehicles based on stochastic driving cycles," Applied Energy, Volume 183, 1 December 2016, Pages 645-658, ISSN 0306-2619, http://dx.doi.org/10.1016/j.apenergy.2016.09.008.

[25] K. Ettihir, M. Higuita Cano, L. Boulon, K. Agbossou, "Design of an adaptive EMS for fuel cell vehicles," International Journal of Hydrogen Energy, Available online 25 August 2016, ISSN 0360-3199, http://dx.doi.org/10.1016/j.ijhydene.2016.07.211.

[26] P. Sharer, A. Rousseau, "Benefits of Fuel Cell Range Extender for Medium Duty Application” EVS27, Oct 2013, Barcelona.

[27] J. Kwon, X. Wang, R. Ahluwalia, A. Rousseau, “ Impact of Fuel Cell System Design Used in Series Fuel Cell HEV on Net Present Value (NPV)" VPPC 2011, Chicago, September 2011.

[28] United States Census Bureau, Vehicle Inventory and Use Survey, 2002. http://www.census.gov/svsd/www/vius/2002.html

[29] Argonne National Laboratory Autonomie Model, 2015. http://www.autonomie.net/.

[30] National Institute of Standards and Technology (NIST) (2011), Thermophysical Properties of Fluid Systems, http://webbook.nist.gov/chemistry/fluid/. 
[31] S. International, "J2601 Fueling Protocols for Gaseous Hydrogen Powered Heavy Duty Vehicles," SAE International, 2014

[32] S. International, “J2601 Fueling Protocols for Light Duty Gaseous Hydrogen Surface Vehicles,” SAE International, 2014

[33] Gangloff, et al., "Design Space Assessment of Hydrogen Storage Onboard Medium and Heavy Duty Fuel Cell Electric Trucks," ASME Fuel Cell Science, Engineering, and Technology Conference, Power and Energy, 2016 Charlotte, NC

[34] S. International, "J2807 Performance requirements for determining tow-vehicle gross combination weight rating and trailer weight rating," SAE International, 2012

[35] Marcinkoski, et al., "Driving an Industry: Medium and Heavy Duty Fuel Cell Electric Truck Component Sizing," EVS29, 2016 Montreal, Canada

[36] http://www.gmpowertrain.com/VehicleEngines/PowertrainProducts.aspx

[37] UQM, "PP145 DataSheet," [Online]. Available: http://www.neweagle.net/support/wiki/docs/Datasheets/UQM/PP145.pdf. [Accessed 102 2016].

[38] A123 Systems, “A123-Systems-AHR32113-Data-Sheet,” [Online]. Available: http://www.a123systems.com/32113-lithiumiron-phosphate-high-power-batteries.htm. [Accessed 10 February 2016].

[39] Walkowicz, K.; Kelly, K.; Duran, A.; Burton, E. (2014). Fleet DNA Project Data. National Renewable Energy Laboratory. http://www.nrel.gov/fleetdna

[40] Truck Index Inc., "2014 Truck Index,” Truck Index Inc., Santa Ana, 2014. 